\title{
Increased epigenetic age in normal breast tissue from luminal breast cancer patients
}

\author{
Erin W. Hofstatter ${ }^{1 *+}$ (D), Steve Horvath ${ }^{2,3+}$, Disha Dalela ${ }^{4}$, Piyush Gupta ${ }^{5}$, Anees B. Chagpar ${ }^{6}$, Vikram B. Wali ${ }^{1}$, \\ Veerle Bossuyt ${ }^{7}$, Anna Maria Storniolo ${ }^{8}$, Christos Hatzis ${ }^{1}$, Gauri Patwardhan ${ }^{1}$, Marie-Kristin Von Wahlde ${ }^{1,9}$, \\ Meghan Butler ${ }^{4}$, Lianne Epstein ${ }^{1}$, Karen Stavris ${ }^{4}$, Tracy Sturrock ${ }^{4}$, Alexander Au ${ }^{4,10}$, Stephanie Kwei ${ }^{4}$ \\ and Lajos Pusztai ${ }^{1}$
}

\begin{abstract}
Background: Age is one of the most important risk factors for developing breast cancer. However, age-related changes in normal breast tissue that potentially lead to breast cancer are incompletely understood. Quantifying tissue-level DNA methylation can contribute to understanding these processes. We hypothesized that occurrence of breast cancer should be associated with an acceleration of epigenetic aging in normal breast tissue.

Results: Ninety-six normal breast tissue samples were obtained from 88 subjects (breast cancer $=35$ subjects/40 samples, unaffected $=53$ subjects/53 samples). Normal tissue samples from breast cancer patients were obtained from distant non-tumor sites of primary mastectomy specimens, while samples from unaffected women were obtained from the Komen Tissue Bank $(n=25)$ and from non-cancer-related breast surgery specimens $(n=28)$. Patients were further stratified into four cohorts: age $<50$ years with and without breast cancer and age $\geq 50$ with and without breast cancer. The Illumina HumanMethylation450k BeadChip microarray was used to generate methylation profiles from extracted DNA samples. Data was analyzed using the "Epigenetic Clock," a published biomarker of aging based on a defined set of $353 \mathrm{CpGs}$ in the human genome. The resulting age estimate, DNA methylation age, was related to chronological age and to breast cancer status.

The DNAmAge of normal breast tissue was strongly correlated with chronological age $(r=0.712, p<0.001)$. Compared to unaffected peers, breast cancer patients exhibited significant age acceleration in their normal breast tissue $(p=0.002)$. Multivariate analysis revealed that epigenetic age acceleration in the normal breast tissue of subjects with cancer remained significant after adjusting for clinical and demographic variables. Additionally, smoking was found to be positively correlated with epigenetic aging in normal breast tissue $(p=0.012)$.

Conclusions: Women with luminal breast cancer exhibit significant epigenetic age acceleration in normal adjacent breast tissue, which is consistent with an analogous finding in malignant breast tissue. Smoking is also associated with epigenetic age acceleration in normal breast tissue. Further studies are needed to determine whether epigenetic age acceleration in normal breast tissue is predictive of incident breast cancer and whether this mediates the risk of chronological age on breast cancer risk.
\end{abstract}

Keywords: Humans, DNA methylation, Genome, Multivariate analysis, Epigenetics, Breast, Epigenomics, Breast neoplasms, Biomarkers, Smoking

\footnotetext{
* Correspondence: erin.hofstatter@yale.edu

†Erin W. Hofstatter and Steve Horvath contributed equally to this work.

${ }^{1}$ Department of Internal Medicine, Section of Medical Oncology, Yale School

of Medicine, 300 George Street, Suite 120, New Haven, CT 06511, USA

Full list of author information is available at the end of the article
}

(c) The Author(s). 2018 Open Access This article is distributed under the terms of the Creative Commons Attribution 4.0 International License (http://creativecommons.org/licenses/by/4.0/), which permits unrestricted use, distribution, and reproduction in any medium, provided you give appropriate credit to the original author(s) and the source, provide a link to the Creative Commons license, and indicate if changes were made. The Creative Commons Public Domain Dedication waiver (http://creativecommons.org/publicdomain/zero/1.0/) applies to the data made available in this article, unless otherwise stated. 


\section{Background}

Breast cancer represents $15 \%$ of all new cancer cases in the US, and with 252,710 estimated new cases in 2017, it has the highest cancer-related incidence in women in the country [1]. Age is one of the strongest risk factors for developing breast cancer and is most frequently diagnosed among women aged 55 to 64 . However, the factors that mediate the effect of chronological age on breast cancer are not fully known. Since epigenetic changes are one of the hallmarks of aging, it is plausible that age-related epigenetic changes may play a role in conferring breast cancer risk.

Historically, studies of the effect of age on breast cancer have been limited by the lack of suitable molecular biomarkers of tissue age. Several studies have explored whether telomere shortening is associated with increased risk and earlier occurrence of familial breast cancer, but the reported effect sizes are relatively weak and require additional validation $[2,3]$.

It has recently been recognized that DNA methylation levels lend themselves for defining a highly accurate biomarker of tissue age ("epigenetic clock") that applies to all human tissues and cell types [4]. This epigenetic biomarker is based on the weighted average DNA methylation level of 353 cytosine-phosphate-guanines (CpGs). The age estimate (in unit of years) is referred to as "DNA methylation age" (DNAmAge) or "epigenetic age." By contrasting DNAmAge with an individual's chronological age, one can define a measure of epigenetic age acceleration. For instance, a woman whose blood tissue has a higher DNAmAge than expected based upon her chronological age is said to exhibit positive age acceleration in blood. Recent studies support the idea that these measures are at least passive biomarkers of biological age. To elaborate, the epigenetic age of blood has been found to be predictive of all-cause mortality [2, 3], lung cancer [5], frailty [6], and cognitive and physical functioning [7]. Further, the utility of the epigenetic clock method using various tissues and organs has been demonstrated in several applications including Alzheimer's disease [8], centenarian status [8, 9], obesity [10], menopause [11], and osteoarthritis [12].

An increasing body of literature suggests that epigenetic age acceleration in blood is predictive of various cancers $[5,13]$ including breast cancer [14]. Cancer greatly disrupts the epigenetic age of the affected (malignant) tissue [4, 15]. While some cancer types are associated with positive age acceleration, others are associated with negative age acceleration $[4,15]$. We have recently shown that malignant breast cancer samples from luminal breast cancer exhibit strong positive age acceleration, which contrasts sharply with the negative age acceleration in basal breast cancers [4, 15]. However, it is unknown whether these age acceleration effects can also be observed in a normal adjacent tissue. Here, we address this question by correlating epigenetic age acceleration in normal breast tissue samples with breast cancer disease status. We find that normal breast tissue samples from breast cancer cases exhibit positive age acceleration compared to normal breast tissue samples from controls. These age acceleration effects are independent of various confounders such as chronological age, ethnicity, age at menarche, number of live births, and menstrual status. In a secondary analysis, we found that smoking is associated with positive epigenetic age acceleration in normal breast tissue.

\section{Methods}

Study specimens

This was a multicenter cross-sectional study performed on fresh frozen samples of normal breast tissue that were collected from four cohorts of women, namely age $<50$ years with and without breast cancer and age $\geq 50$ with and without breast cancer. Normal breast tissue in patients with breast cancer was defined as histologically benign tissue at least $3 \mathrm{~cm}$ away from the primary tumor margin. These samples were obtained prospectively from patients undergoing primary total mastectomy for stage 0-III breast cancer at the Yale Breast Center. Eligible patients were those who had not received chemotherapy, radiation, or endocrine therapy prior to surgery. Normal breast tissue from non-cancer patients was obtained from the Susan G. Komen Tissue Bank at IU Simon Cancer Center and prospectively from women presenting for reduction mammoplasty at Yale New Haven Hospital. Clinical data collected for each subject included age, height, weight, ethnicity, medical history, reproductive history, tobacco and alcohol use, family history of breast cancer, and tumor characteristics. The study was approved by the institutional review board, and written informed consent was obtained from all patients in compliance with the protocol.

The Susan G. Komen Tissue Bank (KTB) is a unique resource that has helped in the understanding of normal breast biology. All participant samples from the KTB group are unaffected tissue donors without a cancer history, and study samples were anonymized in accordance to the protocol. The study population from the hospital prospective cohort included women from all age groups that consented for the study, and patients that had received neoadjuvant treatment were excluded. The tissue samples were further categorized based on tumor molecular subtypes.

\section{Tissue processing}

The breast tissue was sampled as six individual core pieces that were histologically benign, and within $5 \mathrm{~min}$ of procurement, each piece was embedded in a cassette 
that was subsequently placed in a $10 \%$ buffered formalin solution and stored at room temperature. The cores were then flash frozen with liquid nitrogen at $-166.2{ }^{\circ} \mathrm{C}$. The cryo-vials with at least $50 \mathrm{mg}$ of breast tissue per sample were shipped to the lab where the DNA was extracted using the Qiagen All Prep Universal kit. Samples were processed as whole tissue, and DNA was re-extracted from samples that had low DNA yield because of increased fatty tissue. The extracted DNA was then used for bisulfite sequencing experiments.

\section{DNA extraction and methylation studies}

Zymo EZ DNA methylation KIT (Zymo Research, Orange, CA, USA) was used to obtain bisulfite conversion and subsequent hybridization, and scanning was performed with the HumanMethylation450k BeadChip (Illumina, San Diego, CA) and iScan (Illumina) according to the manufacturers' protocol with standard settings. DNA methylation levels $(\beta)$ were quantified using the "noob" normalization method [16]. Specifically, the $\beta$ value was calculated as a ratio of the intensity of fluorescent signals from the methylated and the unmethylated sites:

$$
\begin{aligned}
& \beta=\max (M, 0) /[\max (M, 0)+\max (U, 0)+100] . \\
& M=\text { methylated signals. } \\
& U=\text { unmethylated signal. }
\end{aligned}
$$

Thus, $\beta$ values ranged from 0 to 1 (completely unmethylated to completely methylated).

DNAmAge was then calculated, which has been described in detail elsewhere [4]. Briefly, the epigenetic clock is defined as a prediction method of age based on the DNA methylation levels of 353 CpGs. Predicted age, referred to as DNAmAge, correlates with chronological age in multiple different cell types (CD4+ T cells, monocytes, B cells, neurons), tissues, and organs, including whole blood, brain, breast, kidney, liver, and lung [4].

\section{Internal validation cohort}

Five sets of duplicate samples were analyzed from the cancer cohort in order to examine for concordance.

\section{Statistical methods \\ Patient variables}

Baseline patient characteristics were compared in the cancer and control arm to identify any differences in the study cohort. The continuous variables were analyzed using the unpaired student $t$ test and presented as mean values with $95 \%$ confidence intervals. The categorical variables were analyzed using the chi-square test and presented as frequency percentages. A multivariate logistic regression analysis was then performed to identify significant co-variates for the breast cancer status.

\section{Epigenetic variables}

Despite high correlations, DNAmAge estimates can deviate substantially from chronological age at the individual level; by adjusting for chronological age, we can arrive at a measure of epigenetic age acceleration. DNA methylation age was regressed on chronological age (at the time of breast sample collection) using linear regression. Age acceleration was then defined as raw residuals resulting from the model. Thus, a positive or negative value indicates that a given breast sample is older or younger than expected based on chronological age, respectively. This measure of age acceleration is not correlated with chronological age $(r=0)$ and has a mean value of zero. All measures were calculated using a previously published online version of the DNAmAge calculator. We further calculated the mean methylation levels in the two groups. Pearson correlation statistic of methylation levels against age was calculated for cancer and control groups. Non-parametric tests were performed to test for mean differences in all the epigenetic variables within the two cohorts.

\section{Regression models (univariate, multivariate, and IPWRA)}

A linear regression model was plotted to define the collinearity of the DNAmAge with the age variable. The residuals from the plot were utilized to define the age acceleration residuals as mentioned before. A univariate and multivariate linear regression analysis was then performed to identify predictors of DNAmAge and age acceleration residuals. The $p$ value $<0.05$ was considered statistically significant. A regression adjustment model with inverse probability weighting (IPWRA) was created to address for the potential confounding variables. This treatment effects model was further bootstrapped for 500 repetitions to identify the $95 \%$ confidence intervals of the average treatment effect in population and the potential-outcome means. Average treatment effect in this model can be defined as the additional DNAmAge years of the tissue sample in breast cancer patients compared to controls in a matched population.

\section{Predictive function of epigenetic variables-ROC curves}

Receiver operating characteristic (ROC) were plotted for breast cancer status as the reference variable and age, DNAmAge, mean methylation by sample, age acceleration difference, and age acceleration residuals as classification variables. DeLong method was used to calculate the standard errors, and binomial confidence intervals were calculated. The ROC curves were plotted based on the binomial fit models, and the AUC was calculated. The sensitivity and specificity of the 
most predictive epigenetic variable was then calculated based on the ROC curve.

All the tables, graphs and statistical analysis was performed using STATA version 15.1 (StataCorp LLC, TX, USA). Original datasets used for statistical analysis are included as Additional files 1 and 2.

\section{Results}

\section{Sample characteristics}

Ninety-six normal breast tissue samples were obtained from 88 subjects (breast cancer $=35$ subjects $/ 40$ samples, unaffected $=53$ subjects $/ 53$ samples). Normal tissue samples from breast cancer patients were obtained from distant non-tumor sites of primary mastectomy specimens, while samples from unaffected women were obtained from the Komen Tissue Bank $(n=25)$ and from non-cancer related breast surgery specimens $(n=28)$. Three patients that received neoadjuvant chemotherapy in the cancer arm were excluded from analysis. Five additional samples were taken from specimens with breast cancer to serve as internal controls for studying any variations within the breast tissue. Samples from the breast cancer patients were classified as the "cancer arm," and those from unaffected patients were classified as the "control arm."

\section{Patient demographics}

The baseline characteristics for the cancer arm and control arm have been summarized in Table 1. The mean age of patients was 49.7 years versus 45.9 years in the cancer arm and the control arm, respectively $(p=0.126)$. Most of the patients in our study cohort were Caucasian (86\%) and non-Hispanic (91.4\%). The average body mass index of the cancer group was $27 \mathrm{~kg} / \mathrm{m}^{2}$. Forty percent of patients were ever-smokers, and $62 \%$ are current alcohol users. There was significantly higher alcohol consumption in the control group than the cancer group $(72 \%$ vs $47 \%, p=0.019)$. The patients were mostly premenopausal $(60 \%)$, and $74 \%$ were ever-pregnant. The median live birth count was 2 , and $41 \%$ patients had a history of breastfeeding. The mean age at menarche and mean age at first live birth were not significant between the two cohorts. Within the cancer cohort, patients were randomly distributed in terms of the pathological stage (0-III). Forty-five percent had a positive family history of breast cancer, and $95 \%$ of patients had ER+/PR+ tumors. Her2neu was positive in $7.5 \%$ of tumor samples, while $15 \%$ of patients were not typed for Her2neu. One patient in the control group was BRCA-positive, who had undergone a risk-reduction mastectomy. This patient was excluded from univariate and multivariate analyses. Further multivariate logistic regression analysis revealed that alcohol consumption and post-menopausal status was significantly different in the two cohorts. The details of the analysis have been summarized in Table 2 .

\section{CpG methylation levels and the "epigenetic clock" analysis}

The estimated DNAmAge (derived from the epigenetic clock) based on tissue CpG mean methylation levels highly correlated with the chronological age of the patients at the time of breast tissue collection $(r=0.712$, $p<0.001$, Spearman's correlation test) (Fig. 1), (Table 3). This further confirmed the findings we had published previously that tissue-level methylation can serve as a predictor for the aging process in an individual [17]. Despite an increasing trend, it can be noted that the tissue epigenetic age varies widely for each individual. The cancer cohort showed a higher mean of DNAmAge than the control cohort on univariate analysis $(p=0.021$, Student's $t$ test) and remained statistically significant even after matching for age and smoking status $(p=0.009)$. (Table 3) To eliminate the effect of age, we regressed the DNAmAge values over the age variable to calculate the age acceleration residuals. The cancer cohort exhibited a significant positive age acceleration (positive residual coefficient) correlation compared to the control samples ( $p<0.001$, Student's $t$ test) (Fig. 2d). All samples but one in the cancer cohort were ER+ and/or PR+ (luminal subtype). The single basal subtype did not show a positive age acceleration; however, no conclusion could be drawn from a single value. Three patients from the luminal subtypes were Her2+. Though these three patients had a positive age acceleration with respect to the controls, it was not significantly different from the Her2-negative cancer cohort $(\mathrm{RR}-0.001$, $\mathrm{SE}-0.006, p=0.237)$.

\section{Predictors of DNAmAge and age acceleration residuals-univariate and multivariate analyses and inverse probability weighted regression adjustment (IPWRA) analysis}

A univariate analysis revealed that age $(p<0.001)$, breast cancer status $(p=0.021)$, smoking (pack years) $(p=0.013)$, more than one live birth $(p<0.01)$, and post-menopausal status $(p<0.001)$ were significantly associated with DNAmAge. However, on the multivariate analysis only age $(p<0.001)$, breast cancer status $(p=0.009)$, and smoking pack years $(p=0.022)$ remained significant. Since DNAmAge has a very strong correlation with age of the individual $(r=0.713)$, it can be hypothesized that the effect of breast cancer status or any other covariate will be diminished. To adjust for this, we calculated an age-adjusted measure of DNAmAge as age acceleration residual, which is independent of the age of the patient 
Table 1 Demographic variables of the cancer and control arms

\begin{tabular}{|c|c|c|c|}
\hline Variables & $\begin{array}{l}\text { Breast cancer } \\
N(\%) / \text { mean } \\
(95 \% \mathrm{Cl})\end{array}$ & $\begin{array}{l}\text { Controls } \\
N(\%) / \text { mean } \\
(95 \% \mathrm{Cl})\end{array}$ & $p$ value \\
\hline $\begin{array}{l}\text { Total cohort } \\
\text { samples }\end{array}$ & 40 & 53 & \\
\hline Age (years) & $49.7(46.32-53.02)$ & $45.9(40.29-51.55)$ & 0.126 \\
\hline Age category & & & 0.742 \\
\hline$<50$ years & $24(60 \%)$ & $30(57 \%)$ & \\
\hline$\geq 50$ years & $16(40 \%)$ & $23(43 \%)$ & \\
\hline Ethnicity & & & 0.076 \\
\hline White & $31(78 \%)$ & 49 (92\%) & \\
\hline $\begin{array}{l}\text { African } \\
\text { Americans }\end{array}$ & $4(10 \%)$ & $3(6 \%)$ & \\
\hline Others & $5(13 \%)$ & $1(2 \%)$ & \\
\hline $\begin{array}{l}\text { Ashkenazi } \\
\text { Jew }\end{array}$ & $6(15 \%)$ & $3(6 \%)$ & 0.162 \\
\hline Height (in.) & $64.02(63.10-64.94)$ & $63.96(63.19-64.73)$ & 0.45 \\
\hline Weight (lbs) & $157.22(146.54-167.90)$ & $157.50(148.59-166.41)$ & 0.483 \\
\hline BMI $\left(\mathrm{kg} / \mathrm{m}^{2}\right)$ & & & 0.446 \\
\hline$<18.5$ & $0(0 \%)$ & $1(2 \%)$ & \\
\hline $18.5-24.9$ & $21(53 \%)$ & $22(42 \%)$ & \\
\hline $25.0-29.9$ & $8(20 \%)$ & $17(32 \%)$ & \\
\hline$>30$ & $11(28 \%)$ & $13(25 \%)$ & \\
\hline Tobacco use & & & 0.696 \\
\hline No & $25(63 \%)$ & $31(58 \%)$ & \\
\hline Yes & $15(38 \%)$ & $22(42 \%)$ & \\
\hline $\begin{array}{l}\text { Smoking } \\
\text { (pack years) }\end{array}$ & $3.73(1.06-6.41)$ & $3.86(1.06-6.59)$ & 0.475 \\
\hline $\begin{array}{l}\text { Current } \\
\text { alcohol use }\end{array}$ & & & 0.019 \\
\hline No & $20(52 \%)$ & $15(28 \%)$ & \\
\hline Yes & $18(47 \%)$ & $38(72 \%)$ & \\
\hline $\begin{array}{l}\text { Positive family } \\
\text { history of } \\
\text { breast cancer }\end{array}$ & $18(45 \%)$ & $11(21 \%)$ & 0.012 \\
\hline $\begin{array}{l}\text { Age at } \\
\text { menarche } \\
\text { (years) }\end{array}$ & $12.37(11.72-13.03)$ & $12.54(12.20-12.87)$ & 0.671 \\
\hline $\begin{array}{l}\text { Menopausal } \\
\text { status }\end{array}$ & & & 0.212 \\
\hline $\begin{array}{l}\text { Pre- } \\
\text { menopausal }\end{array}$ & $27(68 \%)$ & $29(55 \%)$ & \\
\hline $\begin{array}{l}\text { Post- } \\
\text { menopausal }\end{array}$ & $13(33 \%)$ & $24(45 \%)$ & \\
\hline Ever pregnant & & & 0.266 \\
\hline No & $8(20 \%)$ & $16(30 \%)$ & \\
\hline Yes & $32(80 \%)$ & $37(70 \%)$ & \\
\hline $\begin{array}{l}\text { No. of times } \\
\text { pregnant }\end{array}$ & $2.6(1.94-3.25)$ & $1.94(1.48-2.39)$ & 0.049 \\
\hline $\begin{array}{l}\text { Age at first } \\
\text { childbirth }\end{array}$ & $25.73(23.24-28.99)$ & $25.61(24.21-27.01)$ & 0.465 \\
\hline
\end{tabular}

Table 1 Demographic variables of the cancer and control arms (Continued)

\begin{tabular}{|c|c|c|c|}
\hline Variables & $\begin{array}{l}\text { Breast cancer } \\
N(\%) / \text { mean } \\
(95 \% \mathrm{Cl})\end{array}$ & $\begin{array}{l}\text { Controls } \\
N(\%) / \text { mean } \\
(95 \% \mathrm{Cl})\end{array}$ & $p$ value \\
\hline \multicolumn{4}{|l|}{ (years) } \\
\hline $\begin{array}{l}\text { Number of live } \\
\text { births }\end{array}$ & $1.97(1.54-2.40)$ & $1.57(1.23-1.92)$ & 0.073 \\
\hline Breastfeeding & & & 0.567 \\
\hline No & $25(63 \%)$ & $30(57 \%)$ & \\
\hline Yes & 15 (38\%) & $23(43 \%)$ & \\
\hline ER/PR status & & & NA \\
\hline $\mathrm{ER}+/ \mathrm{PR}+$ & 38 (95\%) & - & \\
\hline ER+/PR- & $1(2.5 \%)$ & - & \\
\hline $\mathrm{ER}-/ \mathrm{PR}+$ & $0(0)$ & & \\
\hline ER-/PR- & $1(2.5 \%)$ & - & \\
\hline Her2 status & & & NA \\
\hline Not typed & $6(15 \%)$ & - & \\
\hline Her- & 31 (78\%) & - & \\
\hline Her+ & $3(7.5 \%)$ & - & \\
\hline
\end{tabular}

(vide supra). This can be seen in Fig. 2 where age acceleration residual $(p<0.001)$ (Fig. 2d) has a stronger correlation than DNAmAge $(p=0.007)$. A multivariate analysis on age acceleration residuals revealed that only breast cancer status $(p=0.009)$ and smoking pack years $(p=$ 0.022 ) were significant predictors of this epigenetic variable (Table 3). Further, breast cancer status is a much stronger predictor (coefficient $=4.489$ ) of increased age acceleration residual than the smoking pack years (coefficient $=0.178)$ (Table 2).

In a secondary analysis, we examined the correlation of smoking pack years with the DNAmAge of the sampled breast tissue. Age acceleration residual was correlated with tobacco variables $(r=0.21, p=$ 0.047 for total years of smoking, $r=0.26, p=0.014$ cigarettes per day, and $r=0.26, p=0.015$ smoking pack years) in the complete cohort. Similar trends were also noted in the control group (Fig. 3a-f). Though a positive correlation was also noted in the cancer group, it did not reach statistical significance (Fig. 3g-i). These results need to be interpreted with caution as the study was not designed initially to identify smoking as a potential driver of tissue-level epigenetic changes.

Our study population had a selection bias in the age of presentation of the cancer and control population. This can be identified in Fig. 1, where most of the patients in the cancer cohort were in the age group 45 to 65 years whereas the control group were either below or above this age group. To adjust for 
Table 2 Multivariate logistic regression predicting breast cancer

\begin{tabular}{|c|c|c|c|c|c|c|}
\hline \multirow[t]{3}{*}{ Logistic regression } & & & & & Number of obs & \multirow{2}{*}{$\begin{array}{l}57 \\
25.9\end{array}$} \\
\hline & & & & & LR chi2(9) & \\
\hline & & & & & Prob $>x^{2}$ & 0.0021 \\
\hline Log likelihood & & & -25.48 & & Pseudo $R^{2}$ & 0.3369 \\
\hline Breast cancer status & Odds ratio & Std. err. & $z$ & $p>z$ & {$[95 \%$ conf. } & Interval] \\
\hline Age & 1.11 & 0.07 & 1.79 & 0.07 & 0.99 & 1.25 \\
\hline Age of first live birth & 1.04 & 0.08 & 0.50 & 0.62 & 0.89 & 1.22 \\
\hline Age of menarche & 1.33 & 0.38 & 0.99 & 0.32 & 0.76 & 2.34 \\
\hline Current alcohol intake & 0.21 & 0.16 & -2.06 & 0.04 & 0.05 & 0.93 \\
\hline BMl & 0.95 & 0.07 & -0.78 & 0.44 & 0.82 & 1.09 \\
\hline Ever breast fed & 0.61 & 0.50 & -0.60 & 0.55 & 0.12 & 3.06 \\
\hline Family history & 2.37 & 1.91 & 1.07 & 0.28 & 0.49 & 11.51 \\
\hline Post- vs pre-menopausal & 0.01 & 0.02 & -2.60 & 0.01 & 0.00 & 0.32 \\
\hline Smoking (py) & 0.89 & 0.08 & -1.29 & 0.20 & 0.74 & 1.06 \\
\hline
\end{tabular}

this, we created an IPWRA model based on predictors of DNAmAge (linear-dependent outcome variable) and breast cancer status (logistic-dependent treatment variable), accounting for age and smoking as independent outcome variables and current alcohol use and menstrual status as independent treatment variables, to identify the average treatment effect. The iterations were further bootstrapped to 500 reps to calculate the $95 \% \mathrm{CI}$. The analysis revealed that breast

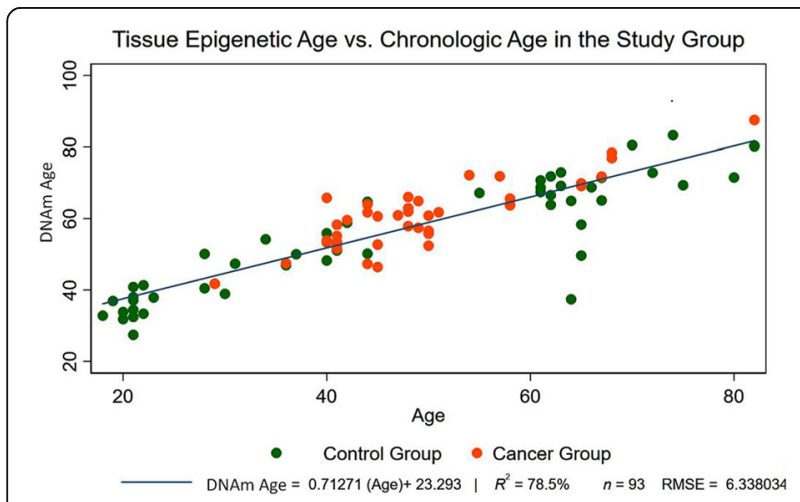

Fig. 1 Tissue epigenetic age versus chronological age. DNA methylation age estimate based on 353 CpGs (y-axis) versus chronological age. All samples are normal breast tissue samples; normal tissue samples from cancer patients were obtained from mastectomy specimens $>3 \mathrm{~cm}$ from tumor margin. Samples (points) are colored by disease status of the donor: red $=$ breast cancer and green $=$ control. $\mathrm{A}$ linear regression line has been added. Age acceleration is defined as raw residual resulting from the regression model, i.e., the (signed) vertical distance to the line. Points above and below the line exhibit positive and negative epigenetic age acceleration, respectively. The high Pearson correlation coefficient $r=0.712,(p<0.001)$ reflects the strong linear relationship between DNAmAge and chronological age at the time of breast sample collection cancer status was significantly associated with a higher DNAmAge score with an average treatment effect of 3.98 years $(p=0.003)$ (Table 4$)$.

\section{Predictive function of the epigenetic variables}

The receiver operating characteristic (ROC) were plotted to identify the accuracy of the epigenetic variables in predicting breast cancer (Fig. 4). Age is considered a strong risk factor for breast cancer; thus, its ROC curve was considered as the baseline for comparison $(A U C=0.527$ ). Like age, DNAmAge $(\mathrm{AUC}=0.578)$ was not a good predictor for breast cancer status, and the curve closely resembled the age binomial fit model. This can be attributed to age being a stronger predictor for DNAmAge than breast cancer. Age difference calculated as the difference of the epigenetic age from the chronological age did not reach desired predictive accuracy as well.

Both mean methylation by sample and age acceleration residuals lead to $\mathrm{ROC}$ curves that lie above the reference line (AUC $=0.687$ and $\mathrm{AUC}=0.689$, respectively) (Fig. 4). The mean age acceleration for the control cohort was -1.67 which corresponded to a sensitivity of $82.5 \%$ and specificity of $49.06 \%$ with a positive likelihood ratio 1.62 and negative likelihood ratio 0.35 . The mean age acceleration residual for cancer cohort was 2.21 which corresponded to a sensitivity of $47.50 \%$ and specificity of $75.47 \%$ with a positive likelihood ratio 1.94 and negative likelihood ratio 0.69 . The tradeoff was achieved at -0.920 with $80 \%$ sensitivity and $57 \%$ specificity.

\section{Discussion}

To our knowledge, this is the first study that has analyzed the epigenetic age variables of the adjacent 
Table 3 Univariate and multivariate analyses of factors affecting DNAmAge and age acceleration residuals

\begin{tabular}{|c|c|c|c|c|c|c|}
\hline & \multicolumn{3}{|c|}{ Univariate analysis } & \multicolumn{3}{|c|}{ Multivariate analysis } \\
\hline & Coef. & Std. err. & $p>t$ & Coef. & Std. err. & $p>t$ \\
\hline \multicolumn{7}{|l|}{ DNAmAge } \\
\hline Age & 0.712 & 0.039 & $<0.001$ & 0.807 & 0.095 & $<0.001$ \\
\hline $\begin{array}{l}\text { Breast cancer } \\
\text { vs controls }\end{array}$ & 6.551 & 2.78 & 0.021 & 4.489 & 1.663 & 0.009 \\
\hline BMI & 0.148 & 0.238 & 0.534 & 0.164 & 0.143 & 0.256 \\
\hline $\begin{array}{l}\text { Current alcohol } \\
\text { use }\end{array}$ & -2.833 & 2.904 & 0.332 & - & - & - \\
\hline Smoking (py) & 0.407 & 0.16 & 0.013 & 0.177 & 0.075 & 0.022 \\
\hline $\begin{array}{l}\text { Age at } \\
\text { menarche }\end{array}$ & 0.322 & 0.959 & 0.738 & 0.948 & 0.49 & 0.057 \\
\hline $\begin{array}{l}\text { Age at first live } \\
\text { birth }\end{array}$ & 0.03 & 0.251 & 0.905 & - & - & - \\
\hline \multicolumn{7}{|c|}{ Count of live births } \\
\hline 1 & 2.292 & 5.494 & 0.678 & -4.92 & 3.268 & 0.137 \\
\hline $1+$ & 14.395 & 2.887 & $<0.001$ & -1.536 & 2.138 & 0.475 \\
\hline Breast fed & 5.286 & 2.83 & 0.065 & - & - & - \\
\hline $\begin{array}{l}\text { Post- vs pre- } \\
\text { menopausal }\end{array}$ & 18.645 & 2.138 & $<0.001$ & -3.982 & 3.006 & 0.19 \\
\hline Hispanic & -5.924 & 5.018 & 0.241 & -3.921 & 3.223 & 0.228 \\
\hline \multicolumn{7}{|l|}{ Race } \\
\hline White & -0.059 & 5.815 & 0.992 & 0.709 & 3.088 & 0.819 \\
\hline $\begin{array}{l}\text { African } \\
\text { Americans }\end{array}$ & -2.142 & 7.643 & 0.78 & 0.196 & 4.219 & 0.963 \\
\hline \multicolumn{7}{|l|}{ Age Acc. Residuals } \\
\hline Age & 0.000 & 0.039 & 1 & 0.095 & 0.095 & 0.324 \\
\hline $\begin{array}{l}\text { Breast cancer } \\
\text { vs controls }\end{array}$ & 3.878 & 1.264 & 0.003 & 4.489 & 1.664 & 0.009 \\
\hline BMI & 0.117 & 0.11 & 0.288 & 0.164 & 0.143 & 0.256 \\
\hline $\begin{array}{l}\text { Current alcohol } \\
\text { use }\end{array}$ & -2.484 & 1.349 & 0.068 & - & - & - \\
\hline Smoking (py) & 0.174 & 0.074 & 0.022 & 0.178 & 0.076 & 0.022 \\
\hline $\begin{array}{l}\text { Age at } \\
\text { menarche }\end{array}$ & 0.358 & 0.454 & 0.433 & 0.949 & 0.491 & 0.057 \\
\hline $\begin{array}{l}\text { Age at first } \\
\text { live birth }\end{array}$ & -0.169 & 0.153 & 0.274 & - & - & - \\
\hline \multicolumn{7}{|c|}{ Count of live births } \\
\hline 1 & -1.598 & 2.9 & 0.583 & -4.92 & 3.268 & 0.137 \\
\hline $1+$ & 0.041 & 1.52 & 0.979 & -1.536 & 2.138 & 0.475 \\
\hline Breast fed & -2.28 & 1.315 & 0.086 & - & - & - \\
\hline $\begin{array}{l}\text { Post vs } \\
\text { pre-menopausal }\end{array}$ & -1.351 & 1.335 & 0.314 & -3.982 & 3.006 & 0.19 \\
\hline Hispanic & 0.636 & 2.342 & 0.786 & -3.921 & 3.223 & 0.228 \\
\hline \multicolumn{7}{|l|}{ Race } \\
\hline White & -1.063 & 2.685 & 0.693 & 0.709 & 3.088 & 0.819 \\
\hline $\begin{array}{l}\text { African } \\
\text { Americans }\end{array}$ & 1.082 & 3.529 & 0.76 & 0.196 & 4.219 & 0.963 \\
\hline
\end{tabular}

Variables in italics are those which reached statistical significance "normal" breast tissue in patients with breast cancer. Our cross-sectional analysis suggests that both epigenetic age acceleration and mean methylation in adjacent breast tissue are predictive of breast cancer status, but these findings require validation in prospective cohort studies. Age, along with breast cancer status and smoking, are independent predictors of epigenetic age of breast tissue.

It is unknown what age-related genetic changes come in effect to increase the incidence of breast cancer in the age group 45-65 years and whether the changes are limited to the site of tumor origin or are present in the entire breast tissue. The concept of field cancerization is well-known in other regions of the body where it has been attributed to exposure to exogenous factors; however, the role of endogenous factors like chronic cell cycling or age-related epigenetic silencing of various genetic pathways in making a tissue more vulnerable to oncogenic transformation is not fully identified. Certain aging processes can accelerate or hinder tumorigenesis in a tissue-specific manner which has been discussed elsewhere [18]. Its specific role in the breast cancer is yet to be elucidated.

Our study highlights the treatment effects analysis which suggests that the normal tissue in the breast cancer patients was at least half a decade older in terms of cumulative epigenetic damage in an age-matched comparison. While this finding may initially seem to have little clinical significance, it is interesting to note that the age acceleration residuals were in complete contrast within the two cohorts. Unaffected individuals had a negative mean age acceleration residual, suggesting that the rate of increase of breast tissue age was slowing down in terms of chronological age, compared to the patients with breast cancer who had positive age acceleration residual, suggesting that the breast tissue was aging at a faster rate than the individual herself. The ROC curves further suggest that higher age acceleration in the breast cancer cohort was specific for breast cancer occurrence. Although our cross-sectional model does not lend itself for dissecting cause and effect relationships, the significant age acceleration observed in patients with luminal breast cancers supports the hypothesis that DNAmAge of normal breast tissue in women with breast cancer increases at a higher rate than in an unaffected individual. As such, our findings suggest that a breast tissue biomarker of accelerated aging may exist that could potentially be associated with the future development of breast cancer.

Future studies will need to test the hypothesis that breast tissue is more predictive of incident breast cancer than blood tissue, which has previously been 




Fig. 2 Comparison of epigenetic variables between cases and controls. Bar plots depict mean epigenetic age and age acceleration ( $y$-axis) versus disease status. a Mean methylation levels of each cohort. b DNAmAge of each cohort. c Age acceleration differences. d Age acceleration residuals. The cancer cohort exhibits a significant positive age acceleration (positive residual coefficient) correlation compared to controls

shown to have a positive, but relatively weak, predictive association [14]. This hypothesis is indirectly supported by the finding that DNA methylation levels in breast tissue are more predictive of the endogenous hormonal milieu in unaffected women compared to blood [19]. Thus, it will be interesting to study whether DNA methylation changes precede actual occurrence of the breast cancer in patients with hormone-responsive breast cancers.

The positive association of smoking with the DNAmAge as well as age acceleration residual is an interesting and unexpected finding in our study. Previous studies failed to detect such an effect in blood [20], liver, or adipose tissue [10]. Taken together, these findings corroborate the hypothesis that many stress factors affect epigenetic age acceleration in a tissue-specific manner. Ever-smokers have been found to have a modest increase in the incidence of breast cancer, particularly in females who started smoking in their adolescence. Although our study does not include data on the exact time interval since smoking initiation and/or smoking cessation and acquisition of data, the association of an overall impact of smoking on DNA methylation is intriguing and merits further study.

We recently published our findings that breast tissue ages faster than blood in unaffected women, as measured by DNA methylation [17]. From the current study, we further extend our understanding of the normal breast tissue, where we identify that patients with hormone-responsive breast cancer have higher epigenetic age acceleration compared to age-matched controls. Given that breast tissue age could be considered a function of multiple variables orchestrating in sync in response to endogenous and exogenous factors during an individual's lifetime (such as age of menarche, use of hormone replacement therapy, alcohol use, and others), epigenetic 


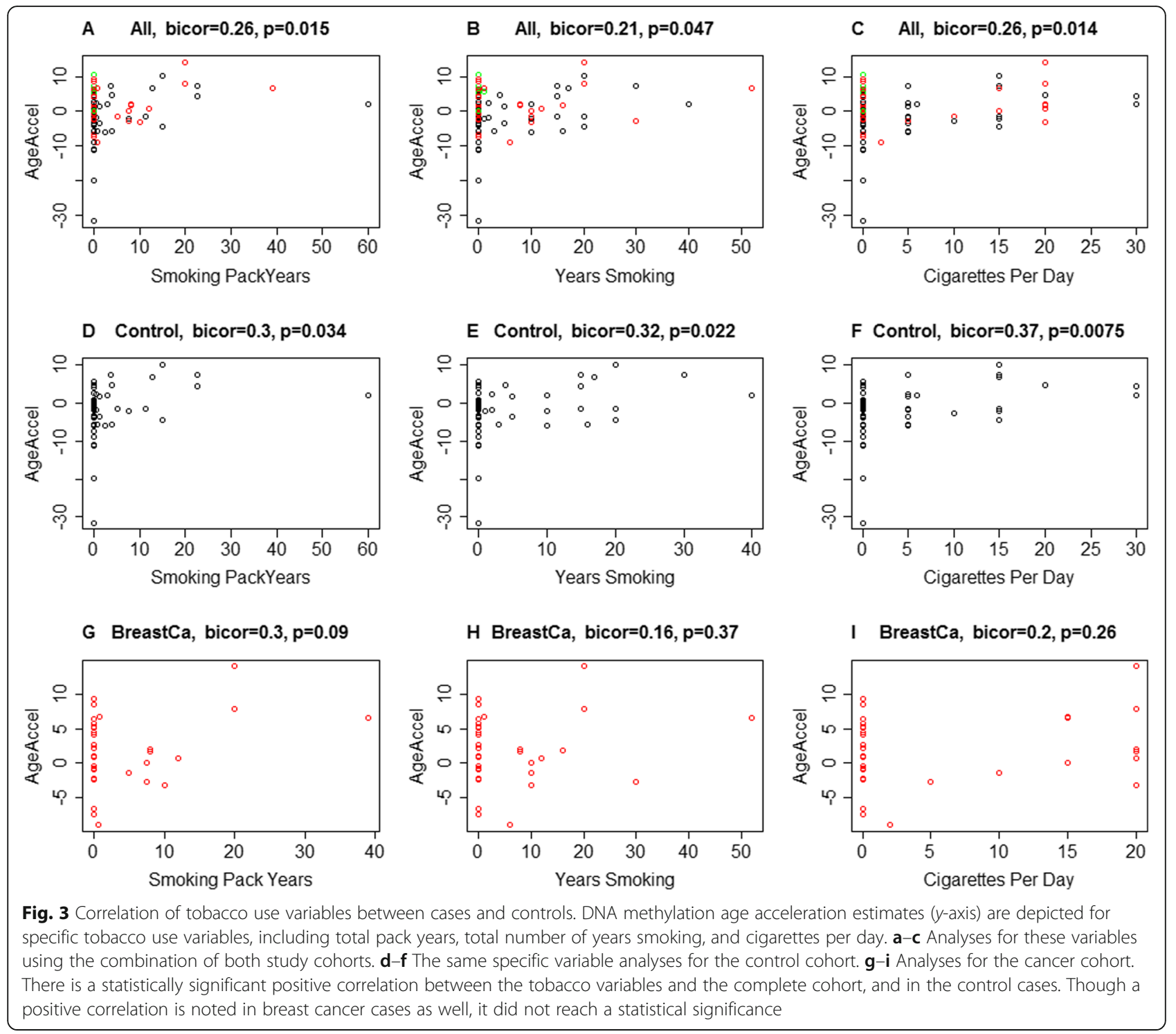

aging may serve as a useful surrogate marker of this changing internal milieu, and offer insight into future breast cancer risk.

We acknowledge the limitations of our study, including the aforementioned small sample size and inability to extrapolate findings to all breast cancer subtypes. Our study involved mainly luminal breast cancer samples. We had one ER-negative/PR-negative sample (which exhibited negative age acceleration) and one ER +/PR-negative sample, and thus, no definite conclusions could be drawn from them. We were also not able to evaluate the effect of BRCA mutations on epigenetic age acceleration since our study involved only a single BRCA mutation carrier who had not (yet) developed breast cancer at the time of sample collection. Further, no significant correlation could be drawn based on the

Table 4 Regression adjustment model with inverse showing average treatment effects (ATE) and potential-outcome mean (POmean)

\begin{tabular}{llllllr}
\hline DNAmAge & Groups & Coef. & Bootstrap & $z$ & $p>z$ & [95\% conf. interval] \\
& & & Std. err. & & & \\
ATE & Cancer vs control group & 3.98337 & 1.333459 & 2.99 & 0.003 & 1.369837 \\
POmean & Control & 55.60416 & 1.642661 & 33.85 & 0 & 52.38461 \\
\hline
\end{tabular}

Treatment-effects estimation: Number of obs = 85; Estimator: IPW regression adjustment; Outcome model: linear; Treatment model: logit; Bootstrap Iterations: 500 


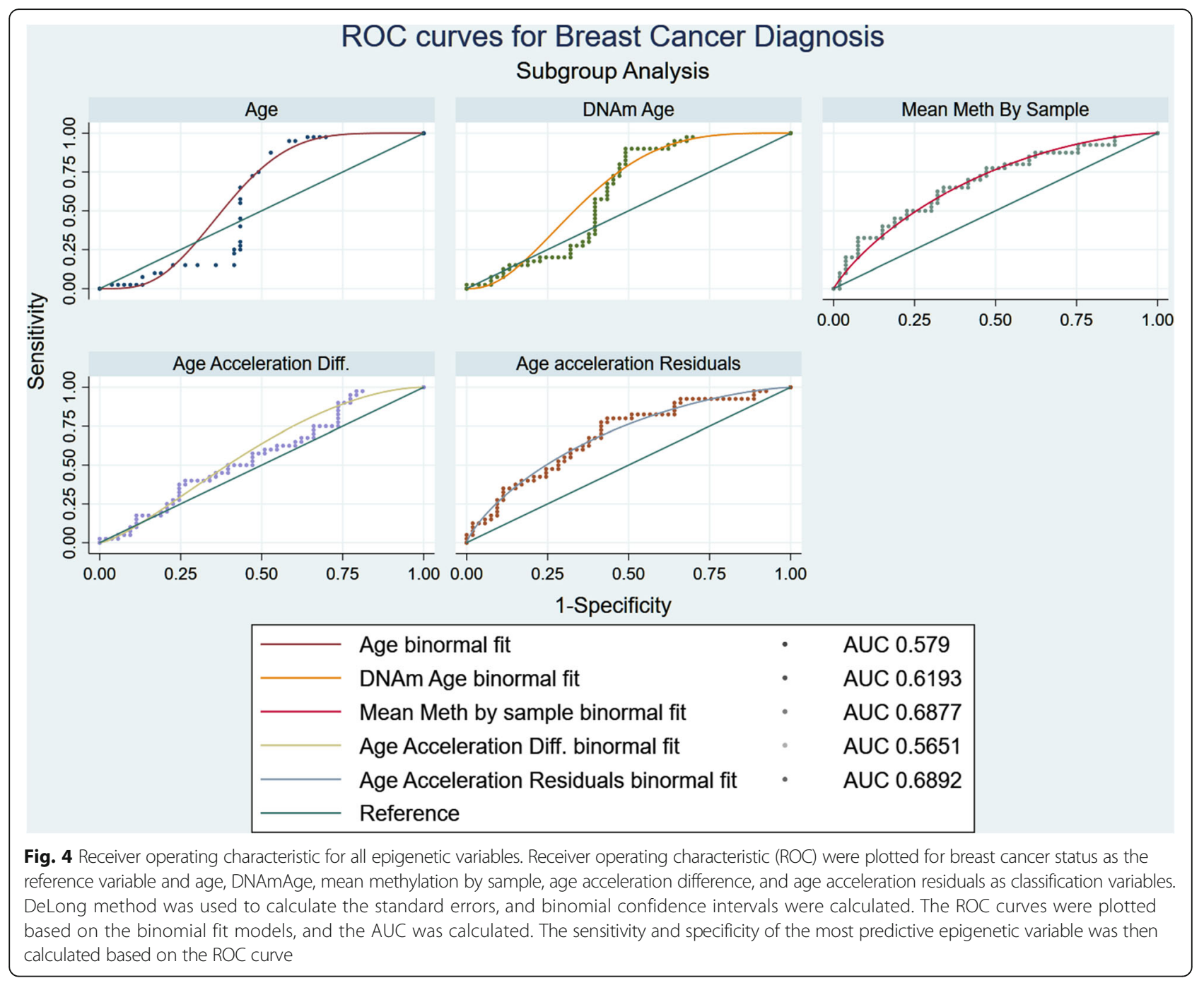

pathologic stage of the tumor as the sample size was not powered for such an analysis. An additional limitation of our study was the difference in age distribution of the cancer cohort as compared to the unaffected cohort, though statistical measures were taken to account for this difference. Future studies with closely age-matched cohorts would be helpful to corroborate our findings. Finally, and of note, we did not isolate any specific cell type within the whole breast sample for the epigenetic age analysis. Thus, we cannot account for the specific cell type, if any, that is primarily responsible for the DNAmAge acceleration in the normal breast. Future studies should be considered to determine the epigenetic ages of individual cell types, as compared to whole tissue epigenetic age analysis.

\section{Conclusions}

In summary, our study demonstrates that epigenetic age acceleration of the "normal" breast tissue in patients with luminal breast cancer was significantly higher than that of unaffected women. We also observed that the difference was maintained when adjusted for potential clinical confounders. Further larger prospective studies will be required to identify the temporal trend of the observed epigenetic aging and its possible use as a predictive biomarker.

\section{Additional files}

Additional file 1: Subject clinical datafile. (XLSX 25 kb)

Additional file 2: Raw statistical datafile. (XLSX 27 kb)

\section{Abbreviations}

AUC: Area under the curve; Cl: Confidence interval; CpGs: Cytosinephosphate-guanines; DNAmAge: DNA methylation age; ER: Estrogen receptor; IPWRA: Inverse probability weighted regression adjustment; KTB: Komen Tissue Bank; PR: Progesterone receptor; ROC: Receiver operating characteristic

\section{Acknowledgements}

The authors wish to acknowledge Jill Henry and Theresa Mathieson of the Komen Tissue Bank for their assistance in sample acquisition, and Jaime 
Miller and Guilin Wang of the Yale Center for Genome Analysis for their assistance in DNA methylation tissue analysis.

\section{Funding}

This work was supported by the Terri Brodeur Breast Cancer Research Foundation (Hofstatter), the Lion Heart Foundation (Hofstatter), and the NCl P30 Cancer Clinical Investigator Team Leadership Award (Hofstatter). Additional support came from NIH/NIA 5R01AG042511-02 (Horvath) and NIH/NIA U34AG051425-01 (Horvath). The funding bodies played no role in the design and conduct of the study; the collection, management, analysis, and interpretation of the data; preparation, review, or approval of the manuscript; and decision to submit the manuscript for publication. EH received philanthropic funding from Chute for the Cure.

\section{Availability of data and materials}

The datasets used and/or analyzed during the current study are available as Additional file 1 and Additional file 2.

\section{Authors' contributions}

EH and LP contributed to the conception and design. EH, AC, WW, VB, AS, $G P, M V W, M B, L E, K S, T S, A A$, and SK contributed to the acquisition of data. $\mathrm{EH}, \mathrm{SH}, \mathrm{DD}, \mathrm{PG}, \mathrm{CH}$, and $\mathrm{LP}$ contributed to the analysis and interpretation of data. $E H, S H, D D, P G, A C, V W$, and $L P$ contributed to the manuscript writing/ revision. All authors read and approved the final manuscript.

\section{Ethics approval and consent to participate}

This study was approved by the Yale University School of Medicine Institutional Review Board, and written informed consent was obtained from all patients in compliance with the protocol.

\section{Consent for publication}

Not applicable.

\section{Competing interests}

The employer of SH, the Regents of the University of California, hold a patent on the epigenetic clock method which names $\mathrm{SH}$ as inventor. The other authors declare that they have no competing interests.

\section{Publisher's Note}

Springer Nature remains neutral with regard to jurisdictional claims in published maps and institutional affiliations.

\section{Author details}

'Department of Internal Medicine, Section of Medical Oncology, Yale School of Medicine, 300 George Street, Suite 120, New Haven, CT 06511, USA. 2Department of Human Genetics, David Geffen School of Medicine, University of California Los Angeles, Los Angeles, CA 90095, USA. ${ }^{3}$ Department of Biostatistics, Fielding School of Public Health, University of California Los Angeles, Los Angeles, CA 90095, USA. ${ }^{4}$ Department of Pharmacology, Yale School of Medicine, 333 Cedar Street, New Haven, CT 06511, USA. ${ }^{5}$ Department of Surgery, Memorial Sloan Kettering Cancer Center, New York 10065, USA. ${ }^{6}$ Department of Surgery, Yale School of Medicine, 330 Cedar Street, New Haven, CT 06511, USA. ${ }^{7}$ Department of Pathology, Yale School of Medicine, 330 Cedar Street, New Haven, CT 06511, USA. ${ }^{8}$ Department of Internal Medicine, Indiana University Melvin and Bren Simon Cancer Center, Indianapolis, IN 46202, USA. ${ }^{9}$ Department of Obstetrics and Gynecology, Münster University Hospital, Münster, Germany.

${ }^{10}$ Department of Clinical Surgery, Perelman School of Medicine, University of Pennsylvania, Philadelphia, PA 19104, USA.

Received: 28 December 2017 Accepted: 23 July 2018

Published online: 29 August 2018

\section{References}

1. Howlader N, Noone AM, Krapcho M, Miller D, Bishop K, Kosary CL, Yu M, Ruhl J, Tatalovich Z, Mariotto A, Lewis DR, Chen HS, Feuer EJ, Cronin KA (eds). SEER Cancer Statistics Review, 1975-2014, National Cancer Institute. Bethesda, MD, http://seer.cancer.gov/csr/1975 2014/, based on November 2016 SEER data submission, posted to the SEER web site, April 2017.

2. Pellatt AJ, Wolff RK, Torres-Mejia G, John EM, Herrick JS, Lundgreen A Baumgartner KB, Giuliano AR, Hines LM, Fejerman L, et al. Telomere length, telomere-related genes, and breast cancer risk: the breast cancer health disparities study. Genes Chromosomes Cancer. 2013;52(7):595-609.

3. Martinez-Delgado B, Yanowsky K, Inglada-Perez L, Domingo S, Urioste M, Osorio A, Benitez J. Genetic anticipation is associated with telomere shortening in hereditary breast cancer. PLoS Genet. 2011;7(7):e1002182.

4. Horvath S. DNA methylation age of human tissues and cell types. Genome Biol. 2013;14:R115.

5. Levine ME, Hosgood HD, Chen B, Absher D, Assimes T, Horvath S. DNA methylation age of blood predicts future onset of lung cancer in the women's health initiative. Aging (Albany NY). 2015;7(9):690-700.

6. Breitling LPH, Saum KU, Perna L, Schöttker B, Holleczek B, Brenner H. Frailty is associated with the epigenetic clock but not with telomere length in a German cohort. Clin Epigenetics. 2016;8:21. https://doi.org/10.1186/s13148-016-0186-5.

7. Marioni RE, Shah S, McRae AF, Ritchie SJ, Muniz-Terrera G, Harris SE. The epigenetic clock is correlated with physical and cognitive fitness in the Lothian Birth Cohort 1936. Int J Epidemiol. 2015;44(4):1388-96. https://doi. org/10.1093/ije/dyu277.

8. Levine ME, Lu AT, Bennett DA, Horvath S. Epigenetic age of the pre-frontal cortex is associated with neuritic plaques, amyloid load, and Alzheimer's disease related cognitive functioning. Aging (Albany NY). 2015;7(12):1198-211.

9. Horvath S, Mah V, Lu AT, Woo JS, Choi OW, Jasinska AJ, Riancho JA, Tung S, Coles NS, Braun J, et al. The cerebellum ages slowly according to the epigenetic clock. Aging (Albany NY). 2015;7(5):294-306.

10. Horvath S, Erhart W, Brosch M, Ammerpohl O, von Schonfels W, Ahrens M, Heits N, Bell JT, Tsai PC, Spector TD, et al. Obesity accelerates epigenetic aging of human liver. Proc Natl Acad Sci U S A. 2014;111(43):15538-43.

11. Levine ME, Lu AT, Chen BH, Hernandez DG, Singleton AB, Ferrucci $L$, Bandinelli S, Salfati E, Manson JE, Quach A, et al. Menopause accelerates biological aging. Proc Natl Acad Sci U S A. 2016;113(33):9327-32.

12. Vidal L, Lopez-Golan Y, Rego-Perez I, Horvath S, Blanco FJ, Riancho JA, Gomez-Reino JJ, Gonzalez A. Specific increase of methylation age in osteoarthritis cartilage. Osteoarthr Cartil. 2016;24:S63.

13. Zheng Y, Joyce BT, Colicino E, Liu L, Zhang W, Dai Q, Shrubsole MJ, Kibbe WA, Gao T, Zhang Z, et al. Blood epigenetic age may predict cancer incidence and mortality. EBioMedicine. 2016;5:68-73.

14. Ambatipudi S, Horvath S, Perrier F, Cuenin C, Hernandez-Vargas H, Le Calvez-Kelm F, Durand G, Byrnes G, Ferrari P, Bouaoun L, et al. DNA methylome analysis identifies accelerated epigenetic ageing associated with postmenopausal breast cancer susceptibility. Eur J Cancer. 2017;75:299-307.

15. Horvath S. Erratum to: DNA methylation age of human tissues and cell types. Genome Biol. 2015;16:96.

16. Triche TJ, Weisenberger DJ, Van Den Berg D, Laird PW, Siegmund KD. Lowlevel processing of Illumina Infinium DNA methylation BeadArrays. Nucleic Acids Res. 2013;41(7):e90.

17. Sehl ME, Henry JE, Storniolo AM, Ganz PA, Horvath S. DNA methylation age is elevated in breast tissue of non-cancer affected women. Breast Cancer Res Treat. 2017;164(1):209-19.

18. de Magalhaes JP. How ageing processes influence cancer. Nat Rev Cancer. 2013;13(5):357-65.

19. Johnson KC, Houseman EA, King JE, Christensen BC. Normal breast tissue DNA methylation differences at regulatory elements are associated with the cancer risk factor age. Breast Cancer Res. 2017;19(1):81.

20. Quach A, Levine ME, Tanaka T, Lu AT, Chen BH, Ferrucci L, Ritz B, Bandinelli S, Neuhouser ML, Beasley JM, Snetselaar L, Wallace RB, Tsao PS, Absher D, Assimes TL, Stewart JD, Li Y, Hou L, Baccarelli AA, Whitsel EA, Horvath S. Epigenetic clock analysis of diet, exercise, education, and lifestyle factors. Aging (Albany NY). 2017;9(2):419-46. https://doi.org/10.18632/aging.101168.

Ready to submit your research? Choose BMC and benefit from:

- fast, convenient online submission

- thorough peer review by experienced researchers in your field

- rapid publication on acceptance

- support for research data, including large and complex data types

- gold Open Access which fosters wider collaboration and increased citations

- maximum visibility for your research: over $100 \mathrm{M}$ website views per year

At $\mathrm{BMC}$, research is always in progress.

Learn more biomedcentral.com/submissions 